\title{
Webquest: Uma ferramenta adaptável para a pesquisa na Web
}

Cassiana Fagundes da Silva, Faculdade de Balsas, cassiana@gmail.com

Rafael Rodrigo Mueller, Faculdade de Balsas, rrmueller1975@yahoo.com.br

Resumo. O objetivo desta pesquisa é verificar como a sistemática de Webquest, pode contribuir para que certas habilidades possam ser desenvolvidas e estimuladas nos alunos. Para a concretização deste fato analisaremos este processo através da utilização de uma metodologia orientada de pesquisa que pode ser trabalhada desde o ensino fundamental até o superior, através do favorecimento da relação entre ensino $e$ aprendizagem atentando principalmente para a postura do professor enquanto facilitador deste processo.

Palavras-chave: Ensino Aprendizagem, WebQuest, Internet.

\section{WebQuest: An Adaptive Tool for Web Research}

\begin{abstract}
The goal of this research is to check how the systematic Webquest, can help to ensure that certain skills can be developed and stimulated in students. This fact will examine this process using a search-oriented methodology that can be crafted from elementary school up to the top, by favoring the relationship between teaching and learning works mainly for the position of teacher as facilitator of this process.
\end{abstract}

Keywords: Learning, WebQuest, Internet. 


\section{INTRODUÇÃO}

Cada vez mais o uso das Tecnologias da Informação e Comunicação (TICs) tem beneficiado o processo de ensino e aprendizagem, principalmente no que tange a inserção de estratégias pedagógicas integradas e adequadas aos recursos tecnológicos disponibilizados e que atendam às necessidades dos atores educacionais envolvidos nesse processo.

O que se observa é que o uso das TICs na educação, por si só, não garante sua efetividade na aprendizagem de conceitos e no desenvolvimento de habilidades e competências [Cunha, 2006].

Assim, novas ferramentas, em ambientes como a Internet, são implementadas, discutidas e aplicadas, ao mesmo tempo, é um dos grandes desafios para os profissionais da educação na atual sociedade da informação. Uma das discussões que se faz em torno do uso pedagógico desse recurso é sobre a diferença entre informação e conhecimento. A respeito disto, devemos citar o pensamento de Daniel Boorstin (1980), diretor da Biblioteca do Congresso Americano: "É um lugar comum de nosso tempo afirmar que esta nação precisa de cidadãos bem informados. (...) "Eu, pelo contrário, proponho que precisamos - em qualquer país verdadeiramente livre - de cidadãos que tenham conhecimento".

Larsen (2000, p. 17) diz que "informação, assim como diversão, é artigo de consumo. Esperamos obter de alguém diversão e informação. Não podemos, porém, obter conhecimento". É nesta perspectiva da inovação de conhecimento que se faz necessária a reflexão sobre as possibilidades pedagógicas dos processos técnicos e a ampliação do entendimento do conceito da metodologia WebQuest [Cunha, 2006].

Segundo Dodge (1995), WebQuest (WQ) trata-se de uma metodologia de motivação de alunos e professores para uso da internet voltado para o processo educacional, estimulando a pesquisa, o pensamento crítico e a produção de materiais através do desenvolvimento da autonomia dos alunos. Em síntese, uma WQ parte da definição de um tema e objetivos pelo professor, onde os alunos farão uma pesquisa inicial e disponibilizarão de links selecionados acerca do tema resultando em uma consulta orientada dos alunos. Estes devem ter uma tarefa, exequível e interessante, que norteie a pesquisa.

Este artigo está organizado conforme segue. A seção 2 descreve sucintamente a origem da metodologia bem como seus principais mentores. Os componentes e os tipos na qual esta metodologia é constituída são descritos na seção 3. O desenvolvimento, e as formas de avaliação das WQ são explicados nas seções 4 e 5, respectivamente. A seção 6 apresenta exemplos de utilização da metodologia WQ no Brasil e demais países. As considerações finais do trabalho são encontradas na seção 7 .

\section{ORIGENS E MENTORES}


Segundo Dodge (1995), em uma entrevista dada ao site da revista online Education World, a ideia de conceber uma WebQuest começou quando ele estava lecionado para uma turma de formação de futuros professores em tecnologias, em que o objetivo da unidade curricular era dotar os alunos com conhecimentos acerca da simulação educacional.

Porém, como Dodge não tinha uma cópia do software de simulação ou de meios para mostrá-lo adotou como estratégia de ensino o trabalho em grupo, visando a recolha de dados do software educacional de simulação em diferentes fontes da web. Orientouos ainda, para que escrevessem um relatório de avaliação sobre o projeto, utilizando alguns sites da web que descrevia o software identificando sua base filosófica construtivista.

Realizaram ainda uma secção de chat com um dos donos do software em Nova Iorque, e também uma secção de videoconferência com um professor que havia testado o programa.

Dodge então decidiu separar estas atividades e organizar as informações, propondo uma tarefa onde os alunos deveriam decidir onde e como, o software poderia ser utilizado na escola em que frequentavam.

No entanto ele apenas formou grupos de trabalho, explicou como deveria ser executada a tarefa e deixou que seus alunos analisassem a informação por si só.

\section{COMPONENTES E TIPOS DE UMA WEBQUEST}

Para que o objetivo educacional de uma WQ seja atingido, Dodge (1995) estabeleceu atributos que devem ser apresentados e dispostos na seguinte ordem:

1) uma introdução que prepare o "palco" e forneça algumas informações de fundo;

2) uma tarefa factível e interessante;

3) um conjunto de fontes de informações necessárias à execução da tarefa. Muitos (não necessariamente todos) dos recursos estão embutidos no próprio documento da WQ em forma de 'âncoras' que indicam fontes de informação na Web. As fontes de informação podem ser: especialistas disponíveis via email ou conferências online, base de dados pesquisáveis na rede, livros e/ou documentos, arquivos) acessíveis no ambiente de aprendizagem;

4) uma descrição do processo que os aprendizes devem utilizar para efetuar a tarefa. $\mathrm{O}$ processo deve estar dividido em passos claramente organizados e descritos;

5) alguma orientação sobre como organizar as informações adquiridas. Isto pode aparecer sob a forma de questões orientadoras ou como direções para completar as metas estabelecidas no prazo;

6) uma conclusão que encerre a investigação, demonstre aos alunos o que eles aprenderam e, talvez, os encoraje a levar a experiência para outros campos não explorados dentro da WQ.

Além dessas componentes básicas, as WQ podem ser classificadas de dois tipos, sendo esses diretamente influenciados pelo seu tempo de duração: WQ curtas e longas. 
As WQ de curta duração giram em torno de uma a três aulas e tem como objetivo dispor aos alunos um número significativo de informações e dar sentido a elas. As WQ longas podem durar de uma semana a três meses de trabalho escolar. Seus objetivos são de analisar uma série de informações, transformá-las e reinterpretá-las de modo que a partir do produto final, outros possam ter acesso e utilizar o material disposto.

\section{DESENVOLVIMENTO DA WEBQUEST}

Não há uma fórmula pronta para a criação de produtos nos moldes da proposta metodológica sugerida por Bernie Dodge. Mesmo assim, destacamos uma possível estrutura em torno de fases que são: a) definição do tema; b) revisão das instruções do modelo proposto; c) definição da tarefa; e) determinar as fontes de pesquisa; f) elaboração do processo e dos recursos; g) desenvolvimento da introdução e conclusão; h) finalização da primeira versão; i) Revisão de toda WQ e; j) utilizar, se necessário, outros materiais adicionais.

WQ é uma investigação cujas fontes são, sobretudo, informações veiculadas no ciberespaço. Assim, a primeira coisa a fazer é imaginar conteúdos de saber que possam ser aprendidos com o apoio de recursos existentes na rede mundial de computadores. Mais concretamente, para definir o tema deve: escolher um tema que possa potencializar as aulas, contextualizar o assunto escolhido no currículo e, imaginar uma abordagem que desperte o interesse.

O modelo do WQ tem em comum com a pedagogia de projetos, a ideia de que devemos saber para fazer e não simplesmente aprender por aprender. Por essa razão, a alma de uma WQ é a 'tarefa'. Se a tarefa não estiver bem definida, a WQ não terá um âmbito desafiador capaz de entusiasmar os alunos. Assim, no decorrer do planejamento, convém dedicar bastante tempo no desenvolvimento de uma tarefa que estimule o desafio e a motivação. Criar uma tarefa com essas características exige, sobretudo clareza, compreensão de como funcionam as nossas habilidades em geral e muita criatividade. Tarefas bem concebidas devem exigir que os alunos trabalhem mais que a dimensão 'conhecimento'. Boas tarefas exigirão uma ou mais das dimensões crescentemente complexas nesta ordem: compreensão, aplicação, análise, síntese, avaliação, de acordo com a Taxonomia de Bloom [Rodrigues Jr, 1997].

As fontes preferenciais de informação devem ser recursos disponíveis na Internet. Torna-se fundamental filtrar esses recursos para ficar apenas com aquelas referências que vai utilizar na WQ. Talvez seja conveniente resolver se será necessário utilizar recursos offline. Para tanto, deve: examinar os endereços (links) já selecionados e verificar se há mais endereços que valham a pena considerar e, ao final, ficar apenas com aquilo que realmente contribua com a pesquisa; verificar a necessidade de utilizar fontes não disponíveis na Internet (livros, revistas, artigos, vídeos etc.); estabelecer a lista de recursos (on e off line) que considere adequada para a consecução da 'tarefa'.

No que se refere aos processos, é necessário elaborar um roteiro que irá ajudar os alunos a obterem bons resultados na 'tarefa'. Lembre-se de que o 'processo' é uma espécie de descrição de metodologia, indicando passo a passo a direção que os alunos deverão seguir. Os recursos selecionados serão apresentados na medida em que os alunos necessitarem deles. Na estruturação do item 'processo e recursos', torna-se 
importante especificar o que se espera do trabalho em grupo. Como regra, WQ's são processos de investigação conduzidos por um grupo. Nesse caso, o modo de trabalhar dos grupos a serem constituídos dependerá da natureza da tarefa, de particularidades interessantes, de dinâmicas adequadas para a WQ. Por isso é importante estabelecer com clareza a constituição do grupo, como a dinâmica que deverá ocorrer etc.

$\mathrm{Na}$ maioria das WQ's, a "tarefa" exige visões diferentes do problema onde normalmente isso é representado por papéis característicos cuja representação garante estudos baseados em diferentes perspectivas. É por essa razão que convém definir bem as características de cada papel ou personagens que você criar. Sendo assim, é fundamental que se estabeleça os passos a serem seguidos no estudo das fontes (recursos) e na elaboração do resultado da 'tarefa'.

No que se refere à introdução, após ter uma boa ideia do que os alunos irão fazer, escrever um texto dirigido aos alunos que seja objetivo, direto, com uma linguagem clara e de fácil compreensão. $\mathrm{O}$ texto da introdução deve funcionar como um material para manchetes de jornais, característico por ser direto, provocante, envolvente e motivador. Como regra geral, introduções são textos de um ou dois pequenos parágrafos. Normalmente se escreve a introdução como se esta fosse a primeira parte de um livro didáticos tradicional. Essa é uma prática centrada no assunto e não nos alunos.

Muito próximo à introdução, a conclusão deve ser algo claro, breve e simples. Para concluir a WQ convém destacar uma ou mais das seguintes recomendações: reafirmar aspectos de interesse registrados na introdução; realçar a importância daquilo que os alunos aprenderam; e apontar caminhos que podem ajudar os alunos a continuarem os estudos e investigações sobre o tema.

A parte de avaliação pode ser pensada em dois momentos: a avaliação da WQ em si através de um check-list [Dodge, 1995]; e também a avaliação do objetivo proposto pela WQ, ou seja, a avaliação do desempenho dos alunos.

\section{FERRAMENTAS PARA DESENVOLVIMENTO DE WEBQUEST}

WebQuest não exige softwares específicos além dos utilizados para navegar na rede, produzir páginas, textos e imagens. Isso faz com que seja muito fácil usar a capacidade instalada em cada escola, sem restrição de plataforma ou soluções, centrando a produção de WQ na metodologia pedagógica e na formação de docentes.

No entanto, encontram-se ferramentas de autoria disponíveis para a Web que utilizam métodos voltados para o desenvolvimento de projetos educacionais baseados no modelo estrutural da metodologia $W Q$, conforme mostra a Tabela 1.

Tabela 1 - Ferramentas para autoria de páginas Web voltadas para a WQ

\begin{tabular}{|l|l|}
\hline \multirow{3}{*}{ FILAMENTALITY } & $\begin{array}{l}\text { Em 1996, March inicia o projeto, junto com a empresa AT\&T } \\
\text { Education - Pacific Bell, uma ferramenta de autoria para } \\
\text { desenvolvimento on-line de projetos educacionais, incluindo a } \\
\text { metodologia WQ. } \\
\text { Disponível em http://www.kn.pacbell.com/wired/fil/index.html }\end{array}$ \\
\hline
\end{tabular}




\begin{tabular}{|l|l|}
\hline \multirow{2}{*}{ QUESTGARDEN 1.0 } & $\begin{array}{l}\text { Disponibilizada em } 2005 \text { e produzida pela equipe de tecnologia } \\
\text { educacional da SDSU (San Diego State University) é uma ferramenta } \\
\text { de autoria para a Web, construída com a linguagem de programação } \\
\text { PHP, que permite a elaboração online de uma página Web, seguindo } \\
\text { a estrutura proposta por Dodge (1995) para elaboração de uma WQ. } \\
\text { As páginas Web podem ser excluídas, editadas ou incluídas pelos } \\
\text { educadores-autores para uma ou mais de uma atividade elaborada nas } \\
\text { mais diversas áreas e conteúdo utilizando essa metodologia. } \\
\text { Disponível em http://WQ.org/questgarden/author/ }\end{array}$ \\
\hline $\mathbf{1 , 2 , 3}$ TU WQ & $\begin{array}{l}\text { Sistema disponibilizado por educadores da Espanha com o objetivo } \\
\text { de auxiliar na construção de página Web utilizando a linguagem }\end{array}$ \\
ON LINE & $\begin{array}{l}\text { Hersão impressa ou publicação da mesma em página na Internet, } \\
\text { ensinando aos educadores como proceder nesse sentido, desde a } \\
\text { inclusão de imagens à inserção de links. } \\
\text { Disponível em http://www.aula21.net/Wqfacil/WQ.htm }\end{array}$ \\
\hline INSTANT WQ & $\begin{array}{l}\text { Produzida pela InstantProjects.Org é outra ferramenta on-line de } \\
\text { autoria para Web, em inglês, nos moldes do QuestGarden 1.0. } \\
\text { Construída com a linguagem de programação PHP, sua utilização é } \\
\text { gratuita e disponibiliza um banco de páginas WQ inclusive em língua } \\
\text { portuguesa. } \\
\text { Disponível em http://www.instantprojects.org/WQ/main.php }\end{array}$ \\
\hline
\end{tabular}

Fonte: [Cunha, 2006]

\section{Exemplos do uso da metodologia WebQuest}

Para Cunha (2006), um indicador da popularidade desta metodologia é o número de vezes em que aparece o termo "WebQuest", expressão de significado próprio que dificilmente retorna outros resultados senão os que estão ligados de alguma forma à essa metodologia na Internet.

O Senac ${ }^{1}$ de São Paulo, disponibiliza um site, sobre a metodologia WQ, no entanto, seu maior foco está nos cursos de capacitação para educadores que desejam utilizar essa metodologia, além de avaliar e agrupar por área e conteúdo as WQ enviadas e, por sua vez, avaliadas de acordo com a Figura 1.

\footnotetext{
${ }^{1}$ Disponível em http://webquest.sp.senac.br/

V. $8 \mathrm{~N}^{\circ}$ 3, dezembro, 2010
} 


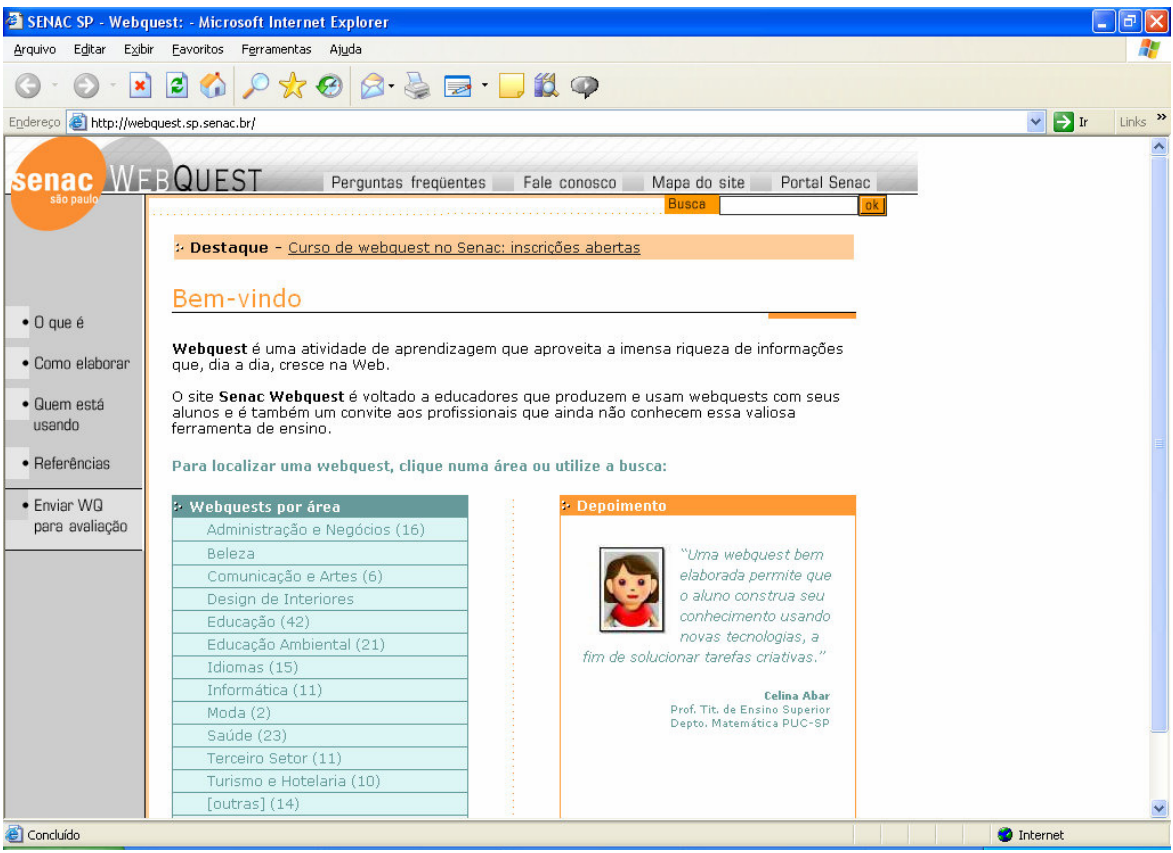

Figura 1 - Site sobre a metodologia WebQuest do Senac de São Paulo.

Por sua vez, tanto o site disponibilizado pela Escola do Futuro (USP) quanto pelo Senac de São Paulo remetem a origem de algumas referências, artigos e entrevistas ao portal educacional sobre WebQuest mantido e disponibilizado pela San Diego State University $^{2}$ (SDSU), sob a coordenação do professor Bernard Dodge, criador dessa metodologia e site de referência sobre pesquisas e trabalhos realizados sobre o tema, conforme Figura 2 [Cunha, 2006].

Outros exemplos de utilização de WQ encontram-se na Europa e alguns países da Ásia que têm desenvolvido trabalhos e pesquisas com a metodologia, destacando-se, em Portugal, a Universidade do Minho e a Universidade de Évora. Além desses países, encontra-se disponível na web um portal ${ }^{3}$ destinado aos professores, alunos, pais e a comunidade em geral, que procuram aprender, consultar e usar as WQ nas suas atividades pedagógicas.

No Brasil, a primeira informação sistemática sobre WQ, em literatura pedagógica no idioma português, apareceu no Guia do Professor para a Internet, obra de Ann Heide e Linda Stilborne no ano de 1998. O modelo criado por Bernie Dodge é uma das partes do capítulo 5: "Trazendo a World Wide Web para a sala de aula". As informações do livro, por causa dos limites próprios dos materiais impressos, não incluem desenvolvimentos mais recentes.

Instituições de ensino têm apresentado suas experiências sobre o trabalho com WQ em seus sites, como o da Universidade Mackenzie ${ }^{4}$.

\footnotetext{
${ }^{2}$ Disponível em http://webquest.sdsu.edu/

${ }^{3}$ Disponível em http://www.portalwebquest.net/

4 Disponível em http://www.mackenzie.com.br/universidade/ffle/webquest
}

V. $8 \mathrm{~N}^{\mathrm{o}} 3$, dezembro, 2010 


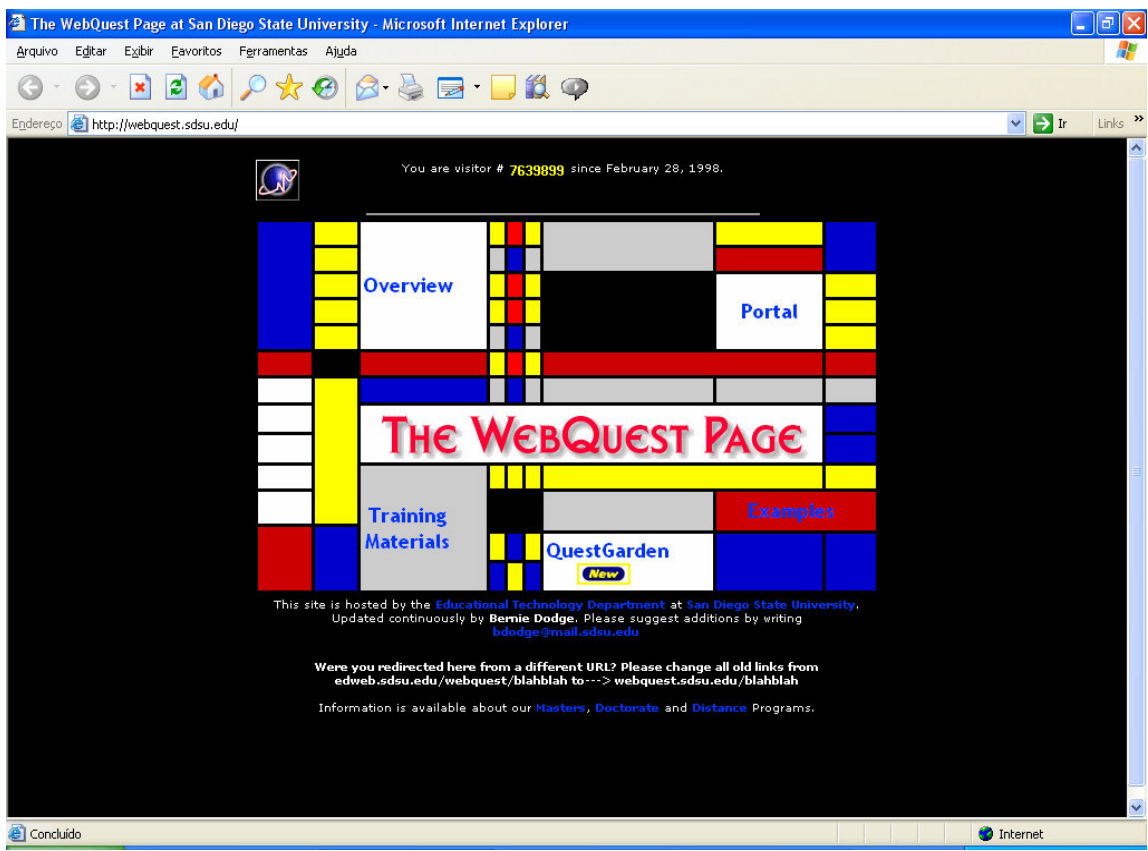

Figura 2 - Site de referência da San Diego State University (SDSU) sobre WQ

A popularidade dessa metodologia mereceu destaque como verbete na Wikipédia, Figura 3, uma enciclopédia multilingual on line livre e colaborativa, ou seja, escrita por várias pessoas, todas elas voluntárias.

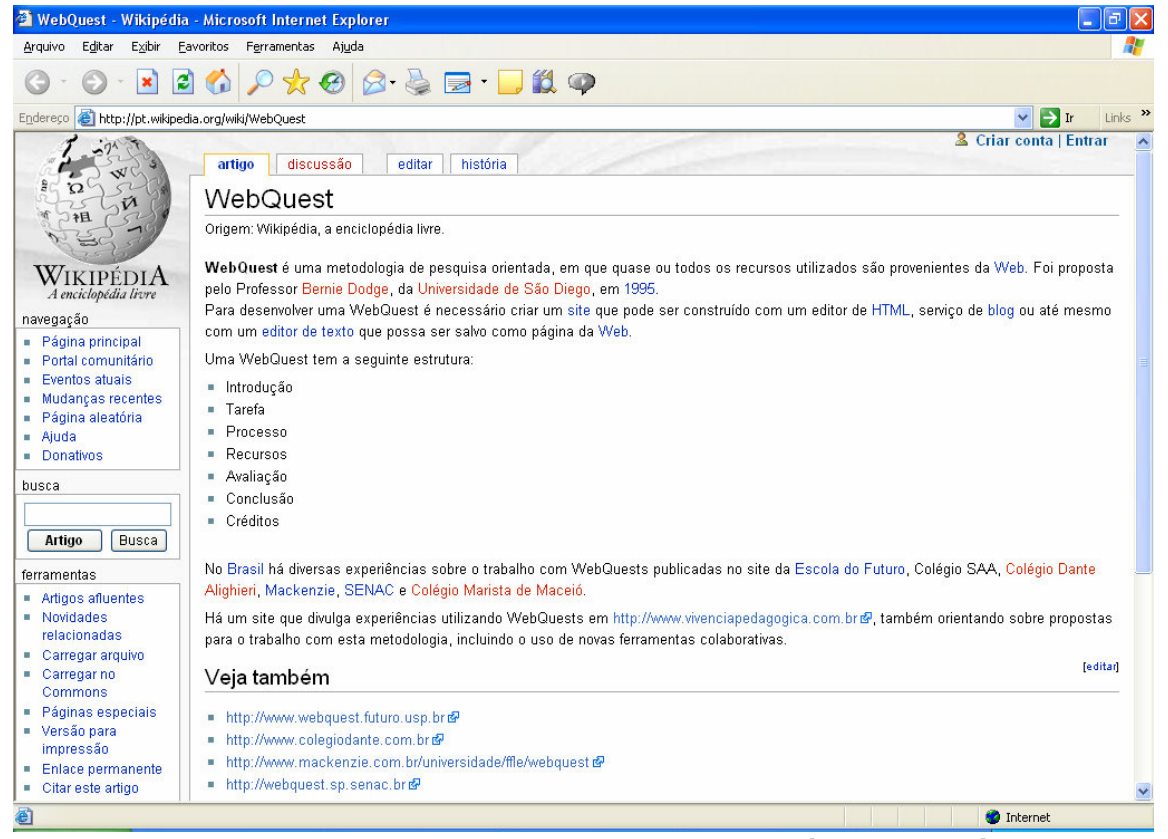

Figura 3 - Verbete WebQuest na enciclopédia Wikipédia

\section{CONSIDERAÇÕES FINAIS}

V. $8 \mathrm{~N}^{\mathrm{o}} 3$, dezembro, 2010 
No que se refere ao objetivo do texto, disponibilizamos algumas habilidades citadas por Dodge (1995) e desenvolvidas a partir do uso de uma Webquest, relacionando-as com as variáveis delimitadas durante o decorrer destes estudos. As WQ's são, sobretudo atividades de grupos, embora possam ser imaginadas investigações individuais aplicáveis a educação à distância e ao ambiente de bibliotecas, o que impreterivelmente remete-nos ao conceito de aprendizagem cooperativa. "Mobilizar energias numa aventura lúdica compartilhada; sentir e fazer sentir; participar entregando o melhor de si e recebendo o melhor dos outros". [Gutiérrez e Prieto, 1991, p.52).

As WQ's podem ser aperfeiçoadas com elementos motivacionais que envolvam a estrutura básica de investigação, dando aos aprendizes um papel a ser desempenhado (Ex.: cientista, detetive ou repórter), criando uma personalidade fictícia com a qual os participantes deverão interagir via presencial, e-mail, chat ou fóruns de debate. A utilização de critérios para auto-avaliação dentro de uma Webquest é de grande valia para o educando, pois "os estudantes que auto-regulam as suas aprendizagens por via da auto-avaliação,confrontando os seus desempenhos com planos hierarquizados de metas e submetas, tendem a manifestar um maior interesse... a desenvolver um maior esforço... a obter melhores resultados". [Cerdeira citado por Petri, 2000, p.15].

As WQ's devem ser planejadas para uma disciplina ou podem abranger uma abordagem interdisciplinar. Uma vez que as abordagens interdisciplinares são um desafio maior que o trabalho numa única área, talvez convenha começar por esta última opção para que consiga reunir mais experiência para trabalhos mais compreensivos. Esta ação pode resultar no favorecimento do modo de fazer educação, pois envolve não só preceitos pedagógicos, como também questiona a postura do professor enquanto facilitador do processo de ensino e aprendizagem.

\section{REFERÊNCIAS}

ARCHELA, R.; ARCHELA, E. WebQuest como Orientação para Construção de Mapas Temáticos. Revista Geografia. Revista do Departamento de Geociências. Universidade Estadual de Londrina Volume 15 - Número 2 - jul./dez, 2006.

BOORSTIN, D. Remarks by Daniel Boorstin, the Librarian of Congress, at White House Conference on Library and Information Science, Journal of information Science, p. 111-112, 1980.

CUNHA, A. C. S. Pensamento sistêmico e tecnologia educacional: a metodologia WebQuest. Dissertação (Mestre em Computação). Mestrado Profissionalizante em Computação. Universidade Estadual do Ceará. Fortaleza. 131f. 2006.

DODGE, B. WebQuests: A Technique for Internet - Based Learning. The Distance Educator. v.1, n. 2, 1995.

GUITIERREZ, P.; PIETRO, F. La mediación pedagógica: apuntes para uma educación a distancia alternativa. San José, Costa Rica: Rádio Nederland Training Center, División de Radio Nederland Internacional. 1991. 
LARSEN, S. Aspectos sociais e psicológicos das Tecnologias Educacionais. II Jornada Catarinense de Tecnologias Educacionais. Florianópolis, 2000.

PRETI, O. Autonomia do aprendiz na educação à distância: Significados e dimensões. Disponível em: <http://www.nead.ufmt.br/documentos/autonomia_-_oreste_I07.doc> . Acesso em: 19 de agosto de 2010.

RODRIGUES JR., J. F. A taxonomia de objetivos educacionais. Brasília: Editora UnB, 1997.

WEBQUEST. Aprendendo na Internet. Disponível em:

$<$ http://www.webquest.futuro.usp.br>_Acesso em: 20 de agosto de 2002 